\title{
BIOCLAIMS standard diet (BIOsd): a reference diet for nutritional physiology
}

\author{
Femke P. M. Hoevenaars • Evert M. van Schothorst • Olga Horakova • \\ Anja Voigt • Martin Rossmeisl - Catalina Pico • Antoni Caimari · \\ Jan Kopecky $\cdot$ Susanne Klaus $\cdot$ Jaap Keijer
}

Received: 11 August 2011/Accepted: 13 December 2011/Published online: 7 January 2012

(C) The Author(s) 2012. This article is published with open access at Springerlink.com

\begin{abstract}
Experimental replication is fundamental for practicing science. To reduce variability, it is essential to control sources of variation as much as possible. Diet is an important factor that can influence many processes and functional outcomes in studies performed with rodent models. This is especially true for, but not limited to, nutritional studies. To compare functional effects of different nutrients, it is important to use standardized, semipurified diets. Here, we propose and describe a standard reference diet, the BIOCLAIMS standard diet. The diet is AIN-93 based, but further defined with dietary and experimental requirements taken into account that allow for
\end{abstract}

F. P. M. Hoevenaars · E. M. van Schothorst $(\bowtie) \cdot$ J. Keijer Department of Human and Animal Physiology,

Wageningen University, Wageningen, The Netherlands

e-mail: Evert.vanschothorst@wur.nl

O. Horakova · M. Rossmeisl · J. Kopecky

Department of Adipose Tissue Biology, Institute of Physiology

Academy of Sciences of the Czech Republic v.v.i.,

Prague, Czech Republic

A. Voigt $\cdot$ S. Klaus

Group of Energy Metabolism, German Institute of Human

Nutrition in Potsdam, Nuthetal, Germany

C. Pico

Molecular Biology, Nutrition and Biotechnology

(Nutrigenomics), University of the Balearic Islands (UIB),

Palma de Mallorca, Spain

C. Pico

CIBER fisiopatología de la Obesidad y Nutrición (CIBEROBN), Palma de Mallorca, Spain

A. Caimari

Centre Tecnologic de Nutrició i Salut (CTNS), TECNIO,

CEICS, Reus, Spain experiments with bioactive food components and natural (non-expensive) labeling. This diet will be implemented by two European research consortia, Mitofood and BIOCLAIMS, to ensure inter-laboratory comparability.

Keywords Semi-purified diet - Nutrient requirements · Rat . Mouse

\section{Introduction}

Nutrition will affect functional outcomes in many studies performed with rodent models. This may already be the case with strong pharmaceutical or toxicological interventions, or when dominant gene knock-outs or knock-ins are considered. When we take obesity, type 2 diabetes, or cardiovascular diseases into consideration, which are multifactorial diseases with a strong dietary background, nutrition becomes even more important. Indeed, dietary intervention studies in wildtype mice and rats were found to give relatively small effects on a variety of parameters such as lipoprotein profiles, biomarkers of inflammation and gene expression responses (Keijer et al. 2010; Patsouris et al. 2006). In addition, "standard" chow diets usually contain poorly specified ingredients that may strongly vary in composition between batches and between providers. For example, a 5,000-fold difference in the level of phytoestrogens has been encountered (Leiter 2009; Thigpen et al. 1999). Moreover, when a chow diet is compared with a semi-purified diet, a remarkable difference in digestibility and thus effective energy intake has been described (Ortmann et al. 2003).

To be able to compare functional effects of different nutrients, it is important to use standardized, semi-purified diets; both as experimental as well as its reference, control diet. This necessity is now widely recognized among 
researchers employing rodents to unravel molecular mechanisms underlying functional effects of nutritional components (Baur et al. 2006; Daniel and Dieck 2004). Indeed, semi-purified control and experimental diets based on the recommendations of the American Institute of Nutrition (AIN93) are increasingly used. While of great importance, these guidelines leave substantial room for variation in a number of dietary constituents that are of significant relevance to molecular and health outcomes of dietary intervention studies (Keijer et al. 2010).

A need to further standardize diets is strongly felt in order to improve comparison of study outcomes and to increase efficiency of resources and animals (Barnard et al. 2009). It is, however, difficult to reach consensus since it implies that individual laboratories have to perform additional initial comparative analyses in ongoing research lines. Despite this, partners in two European research consortia, Mitofood ${ }^{1}$ and BIOCLAIMS, ${ }^{2}$ consisting of, respectively, 38 and 11 partners spread throughout 24 countries in Europe have proposed a common, defined semi-purified AIN93-based reference diet, the BIOCLAIMS Standard Diet (BIOsd), as well as an experimental high-fat diet. Here, we present the choices that have been made, including the underlying rationale, as well as a number of dietary analyses that have been performed on the final formulation of the standard diet.

\section{Materials and methods}

Gross energy determination

Approximately $10 \mathrm{~g}$ of BIOsd (Research Diets Services, Wijk bij Duurstede, NL) and standard chow (Teklad global $16 \%$ protein rodent diet, 2016) were grinded on a $1.0-\mathrm{mm}$ sieve to prepare a homogenate sample for gross energy determination. Samples were left at room temperature for $24 \mathrm{~h}$ to acclimatize for humidity. Samples were measured by IKA C7000 calorimeter (Staufen, Germany) in triplicate or until the deviation was less than $2 \%$. Polyethylene bags were used as standard.

\section{Kahl pellet hardness tester}

Hardness of pellets was assessed by using a Kahl device (Amandus Kahl Nachf., Reinbek/Hamburg, Germany). A pellet is inserted between two bars and due to increasing static pressure applied by a spring, the force $(\mathrm{H}, \mathrm{kg})$ necessary for breakage of the pellet is determined. The average of 12 measurements minus the hardest $\mathrm{H}_{\max }$ and the least hardest $\mathrm{H}_{\text {min }}$ of pellets randomly chosen from the batch is

\footnotetext{
${ }^{1}$ http://www.mitofood.eu.

2 http://www.bioclaims.eu.
}

referred to as "Kahl-hardness" of the pellet, which is given by the following formulae:

$\operatorname{Hardness}(\mathrm{kg})=\frac{\sum n_{1-12} \operatorname{Hardness}(\mathrm{H})_{1-12}-\mathrm{Hmax}-\mathrm{Hmin}}{10}$.

Here, measured pellets differed however in shape. Regular chow is oval shaped $(16 \times 10 \mathrm{~mm})$ while the semi-purified diet is round ( $9 \mathrm{~mm}$ diameter). Chow was tested for breakage on the "flat" side.

Animal experiment

Male C57BL/6JRccHsd mice were delivered from Harlan Laboratories $\mathrm{GmbH}$ to the German Institute of Human Nutrition (DIfE) at 4 weeks of age. Mice were housed individually with ad libitum access to food and water at a temperature of $22^{\circ} \mathrm{C}$ on a $12 \mathrm{~h}$ light-dark cycle. At 6 weeks of age, mice were switched from standard chow diet (Ssniff) to the BIOsd (Research Diets Services, Wijk bij Duurstede, NL). Body weight and composition was determined weekly for 12 weeks using quantitative magnetic resonance (QMR) (Bruker's Minispec MQ10, Housten Texas, USA) as described (Klaus et al. 2005). Animal maintenance and experiments were approved by the animal welfare committee of the Ministry of Agriculture and Environment (State of Brandenburg, Germany).

All experiments were performed in accordance with the directive of the European Communities Council (68/609/ EEC) and the Principles of Laboratory Animal Care (NIH publication no. 85-23, revised 1985).

\section{Results and discussion}

An inventory of changes in nutrient composition compared with the original AIN93 diet was made, and the grounds for making these changes are given below. The general formula of the BIOsd in comparison with AIN diets is shown in Table 1, and the mineral and vitamin mixes of the BIOsd are shown in Tables 2 and 3, respectively.

Fiber

Cellulose is used at $50 \mathrm{~g} / \mathrm{kg}$ according to AIN-93G and AIN-93M (Table 1).

\section{Macro nutrients}

Carbohydrates

In the BIOsd, corn starch has been replaced by wheat starch. This has been done due to a high prevalence of natural stable isotope ${ }^{13} \mathrm{C}$ in corn. This change makes the 
Table 1 BIOCLAIMSsd

\begin{tabular}{|c|c|c|c|}
\hline Composition $\mathrm{g} / \mathrm{kg}$ diet & AIN-93G & AIN-93M & BIOsd \\
\hline Corn starch & 397.486 & 465.692 & - \\
\hline Wheat starch & - & - & 386.5 \\
\hline Casein & 200 & 140 & 220 \\
\hline Dextrinized cornstarch & 132 & 155 & - \\
\hline Maltodextrin & - & - & 100 \\
\hline Sucrose & 100 & 100 & 100 \\
\hline Dextrose & - & - & 50 \\
\hline Soybean oil (no additives) & 70 & 40 & - \\
\hline Fats $^{\mathrm{a}}$ & - & - & 43 \\
\hline Fiber $^{\mathrm{b}}$ & 50 & 50 & 50 \\
\hline Mineral mix (AIN-93G-MX) ${ }^{\mathrm{c}}$ & 35 & 35 & 35 \\
\hline Vitamin mix $(A I N-93-V X)^{d}$ & 10 & 10 & 10 \\
\hline L-Cysteine & 3 & 1.8 & 3 \\
\hline Choline bitartrate & 2.5 & 2.5 & 2.5 \\
\hline $\begin{array}{l}\text { Tert-Butylhydroquinone } \\
\text { (TBHQ) (mg) }\end{array}$ & 14 & 8 & - \\
\hline Total energy $\mathrm{kcal} / \mathrm{kg}$ diet & 3,766 & 3,601 & 3,865 \\
\hline$\%$ as carbohydrates & 64.0 & 75.9 & 66.9 \\
\hline$\%$ as protein & 19.3 & 14.1 & 23.1 \\
\hline$\%$ as fat ${ }^{\mathrm{a}}$ & 16.7 & 10.0 & 10.0 \\
\hline
\end{tabular}

${ }^{a}$ Combination of sunflower oil (70\%), coconut oil (18\%) and flaxseed oil $(12 \%)$

${ }^{\mathrm{b}}$ Cellulose

c For composition, see Table 2

${ }^{\mathrm{d}}$ For composition, see Table 3

diet suitable for metabolic tracer studies using natural enriched corn (Friedrich et al. 2011; Isken et al. 2010; Schmidt and Metges 1985). Furthermore, a combination of maltodextrin, dextrose and sucrose has been used to obtain a pellet with a pleasant hardness for mice (Koopman et al. 1989) (BIOsd vs. chow, Table 4).

\section{Protein}

For the BIOsd a choice has been made to use $220 \mathrm{~g}$ protein/ $\mathrm{kg}$ diet, supplemented with $3 \mathrm{~g}$ L-Cysteine, corresponding to a total of $23 \mathrm{en} \%$ of protein. This protein content avoids potential hyperphagia due to lower protein content ( $\mathrm{Du}$ et al. 2000). L-Cysteine is added to meet the requirements of sulfur amino acid levels (Reeves et al. 1993). The increase in casein also covers the increase in recommendation of sulfur amino acids according to the National Research Council nutrient requirements of Laboratory Animals (National Research Counsil 1995).

Fat

The choice for fats was based on a number of criteria. First, the diet should provide a balance of the essential fatty acids,
Table 2 Contribution of minerals

\begin{tabular}{ll}
\hline Essential mineral elements & $\mathrm{g} / \mathrm{kg} \mathrm{mix}$ \\
\hline Calcium, carbonate, anhydrous, 40.04\% Ca & 357 \\
Potassium phosphate, monobasic, 22.76\% P; 28.73\% K & 196 \\
Potassium citrate, tri-potassium, monohydrate, 36.16\% K & 70.78 \\
Sodium chloride, 39.34\% Na; 60.66\% Cl & 74 \\
Potassium sulfate, 44.87\% K; 18.39\% S & 46.6 \\
Magnesium oxide, 60.32\% Mg & 24 \\
Ferric citrate, 16.5\% Fe & 6.06 \\
Zinc carbonate, 52.14\% Zn & 1.65 \\
Manganous carbonate, 47.79\% Mn & 0.63 \\
Cupric carbonate, 57.47\% Cu & 0.3 \\
Potassium iodate, 59.3\% I & 0.011 \\
Sodium selenate anhydrous, 41.79\% Se & 0.01025 \\
Ammonium paramolybdate, 4 hydrate, 54.34\% Mo & 0.00795 \\
Potential beneficial mineral elements & \\
Sodium meta-silicate, 9 hydrate, 9.88\% Si & 1.45 \\
Chromium potassium sulfate, 12 hydrate, 10.42\% Cr & 0.275 \\
Lithium chloride, 16.38\% Li & 0.0174 \\
Boric acid, 17.5\% B & 0.0815 \\
Sodium fluoride, 45.24\% F & 0.0635 \\
Nickel carbonate, 45\% Ni & 0.0318 \\
Ammonium vanadate, 43.55\% V & 0.0066 \\
Powdered sucrose (carrier) & 221.026 \\
\hline
\end{tabular}

${ }^{a}$ This amount of potassium phosphate supplies only $1,561 \mathrm{mg} \mathrm{P} / \mathrm{kg}$ diet. The remainder $(1,440 \mathrm{mg})$ comes from casein, which contains an average of $0.72 \% \mathrm{P}$. The recommended amount of phosphorus in the diet is $3,000 \mathrm{mg} / \mathrm{kg}$ diet (Reeves et al. 1993)

Table 3 Contribution of vitamins

\begin{tabular}{ll}
\hline Vitamin & $\mathrm{g} / \mathrm{kg} \mathrm{mix}$ \\
\hline Nicotinic acid & 3 \\
Ca Panthothenate & 1.6 \\
Pyridoxine-HCl & 0.7 \\
Thiamin-HCl & 0.6 \\
Riboflavin & 0.6 \\
Folic acid & 0.2 \\
D-Biotin & 0.02 \\
Vitamin B-12 (cyanocobalamin) (0.1\% in mannitol) & 2.5 \\
Vitamin E (all-rac- $\alpha$-tocopheryl acetate) (500 IU/g) & 15 \\
Vitamin A (all-trans-retinyl palmitate) (500 IU/g) & 0.8 \\
Vitamin D (cholecalciferol) (400 IU/g) & 0.25 \\
Vitamin K (phylloquinone) & 0.075 \\
Powdered sucrose (carrier) & 974.655 \\
\hline
\end{tabular}

${ }^{\mathrm{a}}$ Use of the dry, gelatin-matrix form of these vitamins is recommended

linoleic acid (omega-6 fatty acid, n-6;18:2) and linolenic acid (omega-3 fatty acid, n-3;18:3) acid. Bourre et al. suggest a minimal intake of $12 \mathrm{~g}$ linoleic acid and $2 \mathrm{~g} \alpha$-linolenic acid $/ \mathrm{kg}$ diet for rats, which has been recommended 
Table 4 Pellet hardness (kg)

\begin{tabular}{ll}
\hline Diet & Pellet hardness $(\mathrm{kg})$ \\
\hline Chow $^{\mathrm{a}}$ & $21.9 \pm 0.6$ \\
BIOsd & $28.3 \pm 0.8$
\end{tabular}

${ }^{a}$ Harlan Laboratories, Teklad global $16 \%$ protein rodent diet (2016) Values are means \pm SEM

Table 5 Fatty acid profile (\% of $\mathrm{g} / \mathrm{kg}$ diet)

\begin{tabular}{lllll}
\hline & $\begin{array}{l}\text { Coconut } \\
18 \%\end{array}$ & $\begin{array}{l}\text { Sunflower } \\
70 \%\end{array}$ & $\begin{array}{l}\text { Flaxseed } \\
12 \%\end{array}$ & $\begin{array}{l}\text { Total } \\
100 \%\end{array}$ \\
\hline C8:0 & 7 & - & - & 1.3 \\
C10:0 & 6 & - & - & 1.1 \\
C12:0 & 47 & - & - & 8.5 \\
C14:0 & 19 & - & - & 3.4 \\
C16:0 & 10 & 6 & 6 & 6.7 \\
C18:0 & 3 & 4 & 4.5 & 3.9 \\
C18:1 (n-9) & 7 & 25 & 25 & 21.8 \\
C18:2 (n-6) & 1 & 64 & 17 & 47 \\
C18:3 (n-3) & - & - & 50 & 6 \\
n-6/n-3 ratio & & & & 7.8 \\
P/S ratio & & & & 3.1 \\
\hline
\end{tabular}

after revision of the original AIN-93 (Bourre et al. 1989; Reeves 1997). Secondly, a healthy polyunsaturated to saturated fat $(\mathrm{P} / \mathrm{S})$ ratio of at least 2 should be attained (Lee et al. 1989). Thirdly, we selected oils containing neither polyphenols nor carotenes to be able to sensitively intervene with these food bioactive compounds. To meet all these criteria, a combination of sunflower oil (70\%), coconut oil $(18 \%)$ and flaxseed oil $(12 \%)$ has been selected. This results in a (n-6)/(n-3) ratio of 7.8 and a P/S ratio of 3.1 (Table 5). The use of soy oil was considered not appropriate due to its variable polyphenol content. Finally, the gross energy content of the BIOsd diet versus chow is shown in Table 6 .

In addition, it was decided to optionally add $30 \mathrm{mg} / \mathrm{kg}$ cholesterol to the diet (investigator depended), since human diets usually contain cholesterol. This amount of cholesterol corresponds to the amount of cholesterol present in approximately $30 \mathrm{~g}$ lard $/ \mathrm{kg}$ diet and represents average Dutch human intake (Van Schothorst et al. 2005). To our knowledge, there are no known side effects if cholesterol is excluded from the diets.

\section{Micronutrients}

Vitamin and mineral mix

Vitamin and mineral contents follow AIN-93 recommendations and are specified in Tables 2 and 3, respectively.
Table 6 Gross energy content $\mathrm{kJ} / \mathrm{g}$

\begin{tabular}{lll}
\hline Diet & Calculated & Measured \\
\hline Chow $^{\mathrm{a}}$ & 12.6 & $16.8 \pm 0.0478$ \\
BIOsd & 16.2 & $17.5 \pm 0.0016$ \\
\hline
\end{tabular}

${ }^{\mathrm{a}}$ Harlan Laboratories, Teklad global $16 \%$ protein rodent diet (2016) Values are means \pm SEM

The carbohydrate component that is used as a carrier for the vitamin provides $40 \mathrm{kcal} / \mathrm{kg}$ of energy, which has been taken into account for calculating the carbohydrate energy contribution and total energy content (Table 1).

Polyphenols and carotenoids

The oils that are used contain no carotenoids. Sunflower oil contains $1 \mathrm{mg}$ polyphenols per $100 \mathrm{~g}$ oil (De Leonardis et al. 2003), according to the French National Institute for Agricultural Research (INRA) Phenol Explorer Database (INRA 2009). This results in $0.3 \mathrm{mg}$ of polyphenols $/ \mathrm{kg}$ diet $\left(3 \times 10^{-5} \%\right)$, which is considered to be a negligible amount. Sunflower oil contains $41.08 \mathrm{mg} / 100 \mathrm{~g}$ of $\alpha$-tocopherol (vitamin E) (US Department of Agriculture and Service 2010).

\section{Performance in mice}

Using BIOsd during maintenance, similarly to the use of other purified diets, the mice initially lost some weight, as a consequence of the diet switch. After this, the mice displayed a fully normal development and behavior. This was also the case for rats (data not shown).

Figure 1 shows the development of body composition of C57BL/6J mice, which were fed the BIOsd diet from 6 weeks of age for 12 weeks. At 6 weeks (week 6) of age, mice are not yet fully grown. During feeding of the BIOsd, mice gained body weight due to an increase in lean body mass as well as body fat as expected (body mass (g) at week 5: $19.95 \pm 0.24$, at week 18: $24.45 \pm 0.46$; lean mass $(\mathrm{g})$ at week 5: $14.65 \pm 0.20$, at week 18: $17.29 \pm$ 0.34 ; body fat $(\mathrm{g})$ at week $5: 5.30 \pm 0.11$, at week 18 : $7.16 \pm 0.17$, data are mean \pm SEM, $n=12$ ).

The emphasis on a purified diet to reduce experimental variation becomes more and more important due to the use of new technologies such as genomics, proteomics and metabolomics, where small differences can be of major significance for interpretation of the data. But enhanced standardization of general used diets is still necessary for the discovery of effects of phytoestrogens as a powerful variable. Phytoestrogen content of equal open-formula diets can differ up to threefold depending on mill date and 


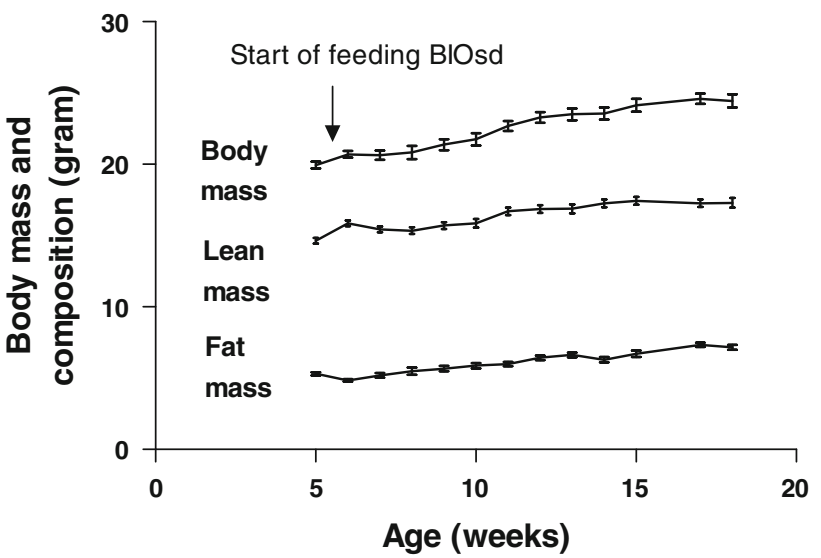

Fig. 1 Body weight and body composition development of C57BL/ $6 \mathrm{~J}$ mice fed BIOsd ad libitum for 12 weeks from 6 weeks of age. Data are mean \pm SEM, $n=12$

use of different commodities (Thigpen et al. 1999). Genistein, a phytoestrogen present in soy for example, displays estrogen receptor activation properties, which are an unwanted effect in dietary studies (Ren et al. 2001). Not only the protein fraction, but also the fat fraction can contain phytoestrogens. Traditional diets often contain soybean oil for its adequate (n-6)/(n-3) ratio. Furthermore, for a proper health and physiological state of the rodents, general rules for $n-6$ and $n-3$ fatty acids and $P / S$ ratio exclude usage of, for instance, palm oil as sole dietary fatty acid ingredient due to a (n-6)/(n-3) ratio of $25: 1$, which is considered to increase the probability of a number of diseases (Simopoulos 2002).

As many partners are interested in the use of a high-fat diet, we also propose a high-fat diet based on the BIOsd, in which a part of the carbohydrate content of wheat starch will be replaced by fat to mimic average daily western human intake (40 en\% fat, 4,700 kcal $/ \mathrm{kg}$ ).

The initial studies that were performed, and those that are still ongoing, show that the diet can be used for maintenance. We have not examined long-term or transgenerational effects, and therefore at present, we do not advise to use the diet as a standard diet in breeding unless further tested. If used during breeding, we recommend to mesh the diet into porridge for easy access for the dams as the BIOsd is harder than standard chow (Table 4); however, it has been reported that this is not necessary for mice post-weaning (Koopman et al. 1989). Indeed, as the data shows, it is adequate for maintenance.

Acknowledgments The authors would like to thank Sven Alferink (Wageningen University) for technical assistance. The research leading to these results has received funding from the European Union's Seventh Framework Programme FP7 2007-2013 under grant agreement no 244995. We would also like to thank the Mitofood (COST Action FA 0602) for making the formulation of this diet possible.
Conflict of interest No conflict of interest or commercial interest is declared by the authors.

Open Access This article is distributed under the terms of the Creative Commons Attribution Noncommercial License which permits any noncommercial use, distribution, and reproduction in any medium, provided the original author(s) and source are credited.

\section{References}

Barnard DE, Lewis SM, Teter BB, Thigpen JE (2009) Open- and closed-formula laboratory animal diets and their importance to research. J Am Assoc Lab Anim 48:709-713

Baur JA, Pearson KJ, Price NL, Jamieson HA, Lerin C, Kalra A, Prabhu VV, Allard JS, Lopez-Lluch G, Lewis K, Pistell PJ, Poosala S, Becker KG, Boss O, Gwinn D, Wang M, Ramaswamy S, Fishbein KW, Spencer RG, Lakatta EG, Le Couteur D, Shaw RJ, Navas P, Puigserver P, Ingram DK, de Cabo R, Sinclair DA (2006) Resveratrol improves health and survival of mice on a high-calorie diet. Nature 444(7117):337-342

Bourre J-M, Francois M, Youyou A, Dumont O, Piciotti M, Pascal G, Durand G (1989) The effects of dietary $\alpha$-linolenic acid on the composition of nerve membranes, enzymatic activity, amplitude of electrophysiological parameters, resistance to poisons and performance of learning tasks in rats. J Nutr 119(12):1880-1892

Daniel H, Dieck HT (2004) Nutrient-gene interactions: a single nutrient and hundreds of target genes (Biological Chemistry). Biol Chem 385(7):571-583

De Leonardis A, Macciola V, Di Rocco A (2003) Oxidative stabilization of cold-pressed sunflower oil using phenolic compounds of the same seeds. J Sci Food Agr 83:523-528

Du F, Higginbotham DA, White BD (2000) Food intake, energy balance and serum leptin concentrations in rats fed low-protein diets. J Nutr 130(3):514-521

Friedrich M, Petzke KJ, Raederstorff D, Wolfram S, Klaus S (2011) Acute effects of Epigallocatechin gallate (EGCG) from green tea on oxidation and tissue incorporation of dietary lipids in mice fed a high fat diet. Int J Obes. doi:10.1038/ijo.2011.136 (in press)

INRA (2009) Phenol-Explorer; Database on polyphenol content in foods. http://www.phenol-explorer.eu/. Accessed 28 Oct 2010

Isken F, Klaus S, Petzke KJ, Loddenkemper C, Pfeiffer AFH, Weickert MO (2010) Impairment of fat oxidation under high- vs. low-glycemic index diet occurs before the development of an obese phenotype. Am J Phys Endoc M 298(2):E287-E295

Keijer J, van Helden YGJ, Bunschoten A, van Schothorst EM (2010) Transcriptome analysis in benefit-risk assessment of micronutrients and bioactive food components. Mol Nutr Food Res 54(2):240-248

Klaus S, Pultz S, Thone-Reineke C, Wolfram S (2005) Epigallocatechin gallate attenuates diet-induced obesity in mice by decreasing energy absorption and increasing fat oxidation. Int $\mathbf{J}$ Obes Relat Metab Disord 29(6):615-623

Koopman JP, Scholten PM, Roeleveld PC, Velthuizen YW, Beynen AC (1989) Hardness of diet pellets and its influence on growth of pre-weaned and weaned mice. Zeitschrift für Versuchstierkunde 32(2):71-75

Lee JH, Fukumoto M, Nishida H, Ikeda I, Sugano M (1989) The interrelated effects of $n-6 / n-3$ and polyunsaturated/saturated ratios of dietary fats on the regulation of lipid metabolism in rats. J Nutr 119(12):1893-1899

Leiter L (2009) Phytoestrogens-uninvited, troublesome guests in scientific research. http://www.researchdiets.com/pdf/Product\% 20Sheets/phytoestrogens_3\%20page.pdf 
National Research Council (1995) Nutrient requirements of laboratory animals 4 th Rev edn

Ortmann S, Prinzler J, Klaus S (2003) Self-selected macronutrient diet affects energy and glucose metabolism in brown fat-ablated mice. Obes Res 11(12):1536-1544

Patsouris D, Reddy JK, Muller M, Kersten S (2006) Peroxisome proliferator-activated receptor alpha mediates the effects of highfat diet on hepatic gene expression. Endocrinology 147(3):15081516

Reeves PG (1997) Components of the AIN-93 diets as improvements in the AIN-76A diet. J Nutr 127(5):838S-841S

Reeves PG, Nielsen FH, Fahey GC Jr (1993) AIN-93 purified diets for laboratory rodents: final report of the American Institute of Nutrition ad hoc writing committee on the reformulation of the AIN-76A rodent diet. J Nutr 123(11):1939-1951

Ren MQ, Kuhn G, Wegner J, Chen J (2001) Isoflavones, substances with multi-biological and clinical properties. Eur J Nutr 40(4): $135-146$
Schmidt HL, Metges CC (1985) Variations of the natural isotope abundance in the diet: causes of artifacts or the base of new possibilities in stable isotope tracer work? Clin Nutr Metab Res Proc 7th congr ESPEN, pp 156-168

Simopoulos AP (2002) The importance of the ratio of omega-6/omega-3 essential fatty acids. Biomed Pharmacother 56(8):365-379

Thigpen JE, Setchell KDR, Ahlmark KB, Locklear J, Spahr T, Caviness GF, Goelz MF, Haseman JK, Newbold RR, Forsythe DB (1999) Phytoestrogen content of purified, open-and closedformula laboratory animal diets. Lab Anim Sci 49(5):530-536

US Department of Agriculture, Service A. R (2010) USDA national nutrient database for standard reference. http://www.nal.usda. gov/fnic/foodcomp/search/

Van Schothorst EM, Franssen-van Hal N, Schaap MM, Pennings J, Hoebee B, Keijer J (2005) Adipose gene expression patterns of weight gain suggest counteracting steroid hormone synthesis. Obesity 13(6):1031-1041 